\title{
BIM Implementation in China: A Case Study Approach
}

\author{
Jiang Bo ${ }^{1, ~ a ~ ", R a n a ~ R a h e e l ~ A f z a l ~ K h a n ~}{ }^{2, b}$, Ahmed Vian ${ }^{2, c}$ and Cheng Zhijun ${ }^{1, d}$ \\ ${ }^{1}$ China Academy of Building Research, 30\#, Bei San Huan Dong Lu, China \\ 2 The University of Salford, The Crescent, Salford, M5 4WT, UK \\ ajiangbo-cabr@163.com, ${ }^{\mathrm{b}}$ R.R.A.Khan@edu.salford.ac.uk, ${ }^{\mathrm{c}}$ V.Ahmed@salford.ac.uk, \\ dchengzhijun@cabr.com.cn
}

Keywords: Building Information Modelling (BIM); Sustainability; Implementation; Strategy; Standards; Case Studies

\begin{abstract}
The term of Building Information Modelling (BIM) has become ubiquitous in construction industry of China. The purpose of this study is to investigate implementation of BIM in construction industry in China, including the BIM strategy, the BIM standards, and the projects that utilized BIM and so on. The methodology for this paper is based on a literature review of the strategy, the standards in relation to BIM and a detailed case study of 30 BIM implementation projects in construction industry in China. A range of key factors that affected the BIM implementation and the initiatives to accelerate the BIM development in China were found in this paper, such as the BIM standards system, the BIM commercial model, BIM contribution to sustainability and so on. From the research findings, some conclusions and recommendations were drawn to explore effective ways to promote the BIM implementation in China.
\end{abstract}

\section{Introduction}

The root of BIM of China can be traced back to 80's last century when software only partly used on simple affairs such as words editing, construction calculation and drawing since mainframe computers were expensive with low speed and few personal computers were available. On this stage, information was created and used by personals. When the information was shared, it often relied on papers or other no-electronic means. So, this period just is the ready stage for BIM.

When it came to 90's, computer performance was improved and the cost was decreased at the same time that allowed the PC to be popularly used in construction industry. However, the software developers take more focus on professional fields or department demands than on the whole enterprise or the circle-life of building, so the information are mainly shared in one department and can't be shared quickly and accurately among deferent departments or deferent professions. Thus, repeat work or conflicting data maybe occurred for the inconvenient information sharing. In this stage, the information sharing and coordination work are mostly implemented within department or profession, so it is called department/ professional BIM.

In 21 century, with the rapid development of Internet technology and wireless network technology, Enterprise or Project collaborative work environment by electronic ways was allowed to be built. Information is tending to be shared on an enterprise or project level. In the future, all the parties, such as Investors, designer, contractor, material/product/labor supplier, construction supervisors, operator, government management department and so on, who are related to a building project, should be an alliance for coordination work. In this stage, the information of different parties and different enterprise will be shared quickly and accurately ${ }^{[1]}$. This is the ultimate aim of BIM which we want to achieve. Therefore, the purpose of this paper to commence a case study on BIM from/within some projects (completed/running by major construction companies) to investigate the current status, application, potential and benefits of BIM that it can and has been offering to Architectural, engineering and construction (AEC) industry. 


\section{Literature review}

BIM is most frequently perceived as a tool for visualizing and coordinating AEC work, avoiding errors and omissions, improving productivity, and supporting scheduling, safety, cost and qualitymanagement on construction projects. It incorporates all the building components, including geometry, spatial relationships, properties and quantities ${ }^{[2]}$.

A popular definition for BIM in China is that, 'information aggregation for individual usage', which is proposed by Qiang Huang who is the vice President of China and the director of China BIM Union. Based on the view of stakeholders, the BIM emphases the aggregation of information, which means information is quickly and directly taken by stakeholders from others in convenient electronic ways throughout the lifecycle of building/infrastructure facilities or assets. Rather than providing a definition as information aggregation, the UK describes BIM through process of electronic object-oriented information. BIM is described as 'process of designing, construction or operating a building or infrastructure asset using electronic object-oriented information' in PAS 1192-2 ${ }^{[3]}$. Despite the difference of the appearance between BIM, the essence of the two concepts is similar and the different just lies in the different perspective to look at BIM. The process and the ways of BIM is emphasised by concept of UK, however the concept in China take more attention on the motive and aim of BIM. This paper regard BIM as an object with aim of "information aggregation for individual usage" and with execution means of 'electronic object-oriented'. Based on this conception of BIM, the history, the strategy, the standards and the cases related to BIM was surveyed.

Countering the potential benefits of BIM to project is the challenges that need to be overcome if effective multi-disciplinary collaborative team working, supported by the optimal use of BIM, is to be achieved. Not least the changing roles of key parties, such as clients, architects, contractors, sub-contractors and suppliers, the new contractual relationships and the re-engineered collaborative processes. One key role likely to be affected by the introduction of BIM is that of the project manager. The impact of an enhanced use of technology on the day-to-day activities of the project manager and the ultimate impact this has on the outputs and outcome of the project are still not clear. There is also the fragmented nature of the construction industry to consider, which means that knowledge gained by a team during the undertaking of a project is often not retained and used on future projects ${ }^{[4]}$. These are structural problems that BIM should be able to overcome.

\section{Research Methodology}

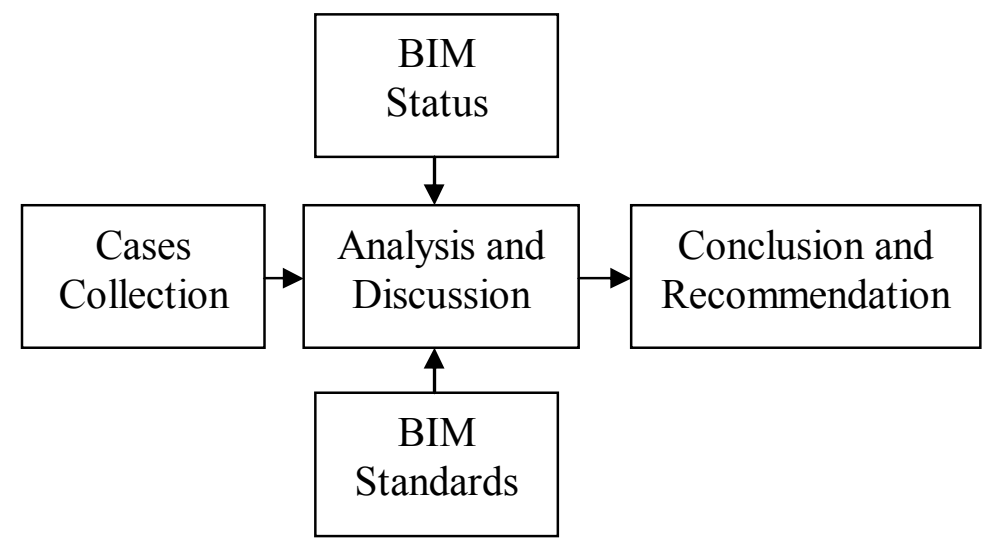

As shown in Fig.1, the methodology for this paper is based on a literature review of the development history, the strategy, the policy, and the standards in relation to BIM in China. Moreover, a detailed investigation of 30 BIM implementation projects was conducted to find current status, the benefits and barriers of BIM implementation. Based on the surveys, this study undertook an analysis and discussion of the key factors of BIM development in China and the initiatives to accelerate the BIM development in China were found.

\section{BIM Status in China}

Many countries have development strategies of BIM and got some degree of achievement on the implement of BIM. In the UK, The Government Construction Strategy accompanied with the 
specification (PAS) 1192 has prompted the development of BIM which have unlocked new more efficient ways of working at all stages of the project life-cycle. In china, although there is no the national unified strategy on BIM, but Ministry of Housing and Urban-Rural Development of the People's Republic of China(MOHURD) have released some documents to promote the BIM development. In addition, some provinces have released some BIM promoting policies which are listed as following. However most of them are lack of details except Shanghai's policy which is a frontier one for its commercialization and comprehensiveness.

The China BIM software and relative tools developing have barely begun. For example, the PKPM developed by China Academy of Building Research has finished the IFC port ${ }^{[5]}$; The Luban software has developed BIM software for construction stage on its own; The Grandsoft software has finished second-development of BIM software based on the Revit, and etc.

According the Business of BIM in China (2015) by Dodge Data \& Analytics, the current Chinese architects are doing more than $30 \%$ of their work in BIM, and the percentage is forecasted to nearly double over the next two years. The report findings demonstrate that, while BIM is relatively new in China, its utilization is growing rapidly, especially among larger firms that can capitalize best on its value currently. It demonstrates that the Chinese market is beginning to experience the benefits of BIM and suggests the potential for China's leadership in BIM use in the future ${ }^{[6]}$.

Table1 BIM Policy Documents in China

\begin{tabular}{|c|c|c|}
\hline Department & \multicolumn{2}{|l|}{ Title of document } \\
\hline MOHURD & \multicolumn{2}{|l|}{ Development Outline of Construction Industry Informatization (2004-2008) } \\
\hline MOHURD & \multicolumn{2}{|l|}{ Development Outline of Construction Industry Informatization (2011-2015) } \\
\hline MOHURD & \multicolumn{2}{|c|}{ Guide to Promote Implementation of BIM in Construction Industry(exposure draft) } \\
\hline $\begin{array}{l}\text { Shanghai } \\
\text { Municipality }\end{array}$ & \multicolumn{2}{|c|}{ Guide to Promote implementation of BIM in Construction Industry } \\
\hline $\begin{array}{l}\text { GuangDong } \\
\text { Province }\end{array}$ & \multicolumn{2}{|l|}{ Notice about Implementation and Popularization of BIM } \\
\hline \multicolumn{3}{|c|}{ Table2 BIM Standards in China } \\
\hline \multicolumn{2}{|c|}{ Name of Standards } & Level/Function Types \\
\hline \multicolumn{2}{|c|}{ Unified Standard for Building Information Model Application } & $\begin{array}{l}\text { National Standard/ } \\
\text { Strategy standards }\end{array}$ \\
\hline \multicolumn{2}{|c|}{ Storage Standard for Building Information model } & $\begin{array}{l}\text { National Standard/ } \\
\text { Foundation Standard }\end{array}$ \\
\hline \multicolumn{2}{|c|}{$\begin{array}{l}\text { Standard for Classification and Coding of Building Constructions Design Information } \\
\text { Model }\end{array}$} & $\begin{array}{l}\text { National Standard/ } \\
\text { Foundation Standard }\end{array}$ \\
\hline \multicolumn{2}{|c|}{ Deliver Standard of Building Design-Information Modeling } & $\begin{array}{l}\text { National Standard/ } \\
\text { Foundation Standard }\end{array}$ \\
\hline \multicolumn{2}{|c|}{ Industry Foundation Classes Platform GB25507-2010 } & $\begin{array}{l}\text { National Standard/ } \\
\text { Foundation Standard }\end{array}$ \\
\hline \multicolumn{2}{|c|}{ Standard for Basic Data Element of Constructional Trade Information } & $\begin{array}{l}\text { Professional standard / } \\
\text { Foundation Standard }\end{array}$ \\
\hline \multicolumn{2}{|c|}{$\begin{array}{l}\text { Shanghai Standard Application of Building Constructions Design Information } \\
\text { Model/Shanghai Standard for Depth and Fee Scale of Building Constructions Design } \\
\text { Information Model/Guangdong Province Untied Application of Building } \\
\text { Constructions Design Information Model/Beijing Standard of Civil Building } \\
\text { Design-Information Modeling/Sichuan Province Deliver Standard of Building } \\
\text { Design-Information Modeling, etc. }\end{array}$} & $\begin{array}{l}\text { Provincial Standards/ } \\
\text { Foundation Standard } \\
\text { Or } \\
\text { application standards }\end{array}$ \\
\hline \multicolumn{2}{|c|}{$\begin{array}{l}\text { Standards of P-BIM Software Technology and Information Exchange (SP-BIMSTIE) } \\
\text { for Architectural Design } \\
\text { SP-BIMSTIE for Concrete Structure Design } \\
\text { SP-BIMSTIE for Concrete Structure Construction } \\
\text { SP-BIMSTIE for Project Supervision } \\
\text { SP-BIMSTIE for Project Cost, etc. }\end{array}$} & $\begin{array}{l}\text { Association Standards } \\
\text { Application standards }\end{array}$ \\
\hline
\end{tabular}




\section{BIM Standards in China}

In China, a number of standards for information technology on BIM have been developed these years. We prefer to sort them into three types (strategy standards, foundation standards, application standards) classified by function and four levels (national standards, professional standards, provincial standards, association standards) classified by issued organization. The strategy standards contains the framework how to develop and implement BIM; Foundation standards are developed for data exchanging, storing and delivering based on information technology, which is mainly used by the BIM tools developer. The application standards guide the practitioners in construction industry how to use the BIM tools and how to implement BIM in life-circle of the building. National standards are issued by national government standardization department; professional standards are issued by MOHURD; provincial standards are issued by the provincial government standardization department; association standards are issued by some association related to construction industry.

There are five national standards: Unified standard for Building Information Model Application, which is a strategy standard to some extent and contains the framework how to implement BIM; Standard for Classification and Coding of Building Constructions Design Information Model, which partly refers to the ISO 12006-2 and ISO 12006-3; Deliver Standard of Building Design-Information Modelling, which partly refers to NBIMS ${ }^{[7]}$; Industry Foundation Classes Platform GB25507-2010 ${ }^{[8]}$ which is equal adoption of ISO/PAS $16739: 2005^{[9]}$ and is the only one having been issued.; Storage Standard for Building Information Model, there is not a draft yet. The last four national standards are foundation standards which supply a basic data exchange technique support for BIM.

Besides the national standards, there are some professional standards, provincial Standards and association standards on BIM are being developed which are listed in the table2.

\section{Case Study}

Data Collection: In order to explore the key factors of BIM implementation, 30 projects which were claimed to have utilized BIM were gathered, as listed in Table3. Among the projects, 28 projects were public building, 1 project was a residential building and 1 project was astronomical infrastructure. From numbers of the types of project, it is evident that the public building is the main project type which utilized BIM.

Table3 Details of the Selected Cases

\begin{tabular}{l|l}
\hline Project Name & Project Name \\
\hline Shanghai Wanke Qibao Square & Guangzhou Zhujiang City Building \\
\hline Jiang Shu Grand Theatre & Yinchuan Rail Station \\
\hline $\begin{array}{l}\text { Nanjing Lukou International Airport Terminal } \\
\text { (Second Phase) }\end{array}$ & Shenyang Xiangyun Heating Power Office Building \\
\hline Fuzhou International Financial Center & Central Conservatory of Music \\
\hline Tianjin Yongli Building & World Expo SAIC GM Pavilion \\
\hline China Zun building & World Expo Austria Pavilion \\
\hline Octopus Seven-star Hotel & Xuzhou Olympic Sports Center Stadium \\
\hline Nanjing Zhengda Thumb Project & Tianjin 117 Building \\
\hline Grand Information Building & Zhongshan Ancient Town Commercial Buildings \\
\hline Beijing Tongzhou Binhe Hospital & Tianjin Architecture Design Institute Building \\
\hline Dahongmen West Road 16\# Project & Beijing Olympic village \\
\hline Urumqi high-speed rail station & Jiuzhou Garden Project(2.1.2 stage) \\
\hline Fuzhou Changshan Wanda Square & China Academy of Building Research Building \\
\hline CNOOC (Shenzhen) Project & China Expo Exhibition complex project \\
\hline Shanghai Tower & Five hundred meters Aperture Spherical Telescope \\
\hline
\end{tabular}


Case Study Results: The Fig.2 shows the proportions of scales of projects which selected. According to the classification standard of design scale of project, buildings with more than $20,000 \mathrm{~m}^{2}$ of total area are called mega-scale projects. Meanwhile, small-scale projects mean buildings with less than $5,000 \mathrm{~m}^{2}$ of total area and the others are middle-scale projects. We can conclude from Fig. 2 that the majority of the BIM projects are mega-scale buildings.

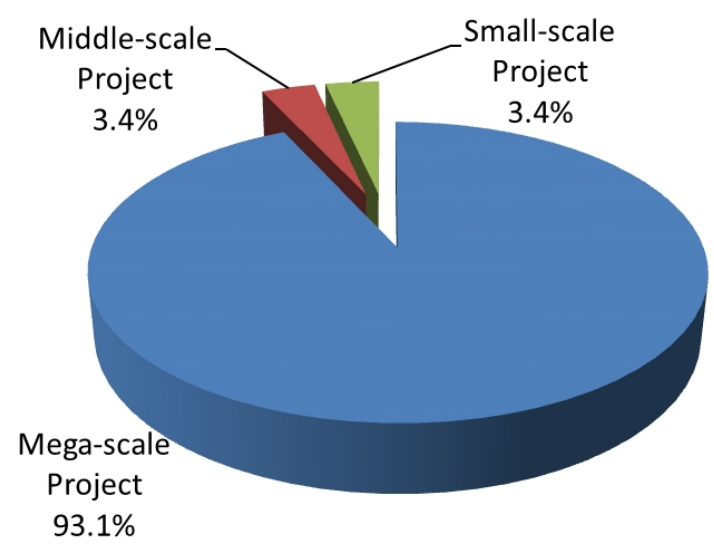

Fig.2 Project Scales

According Fig.3, projects which used BIM in design stage, construction stage and both of these two stages occupy the top three ones in the statistics of application stages of BIM. What should be notable is that BIM used in the operation management is much less than other stages.

In addition, software utilized in BIM projects was surveyed and the results were illustrated in Figure4. There will be little doubt that the software developed by Autodesk, especially Revit, is overwhelming in the BIM software market in China. The native software of Luban and Grandsoft take up a small proportion of software used in BIM projects. Furthermore, Grandsoft is re-developed based on the products of Autodesk, such as Revit. Only Luban is totally developed by domestic company of China which has some advantages on construction management because most of the oversea software is incompatible with the construction management system of China.

At last, we surveyed the benefits from BIM claimed by the project teams. Most of the project teams mentioned the advantage of reducing the errors and omissions in construction documents. Also, better design solutions and coordination improvement during design and construction are two main benefits which are valued by the project teams.

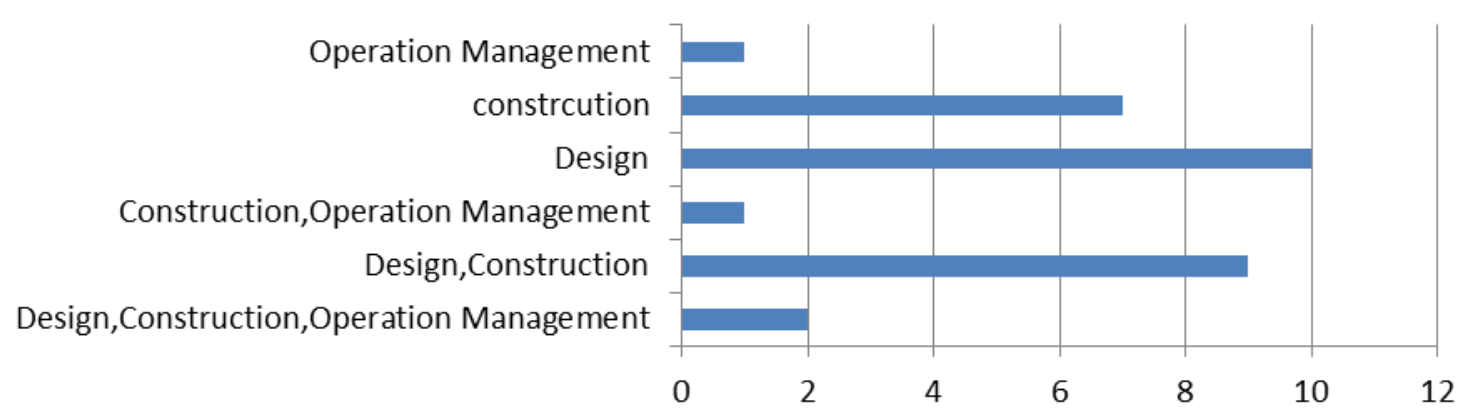

Fig.3 Application Stages of BIM

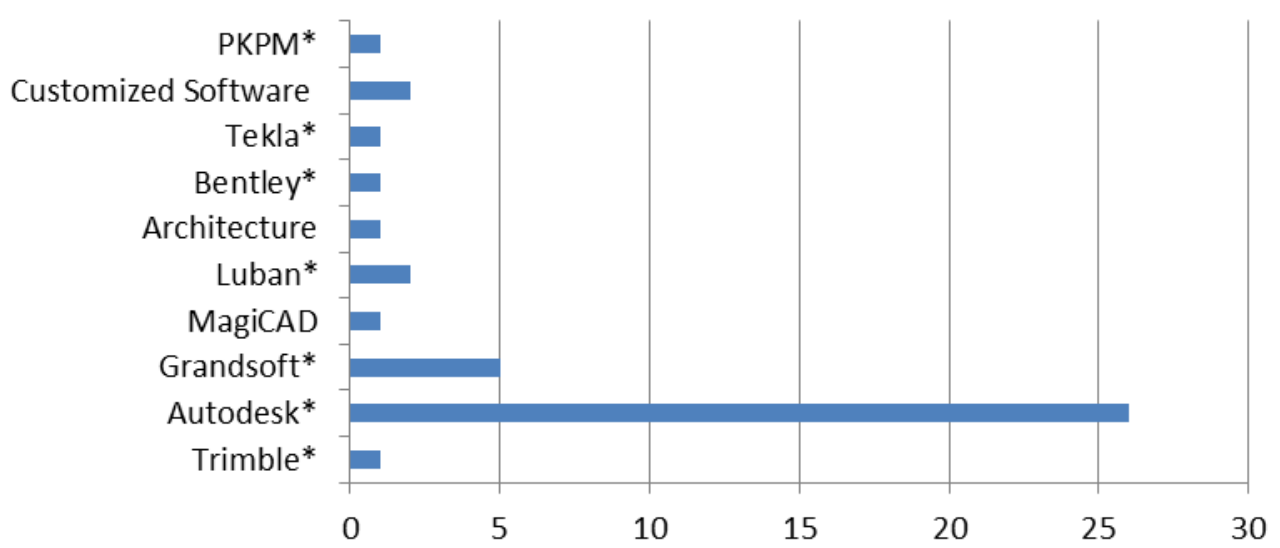

Fig.4 Software utilized in BIM Projects 


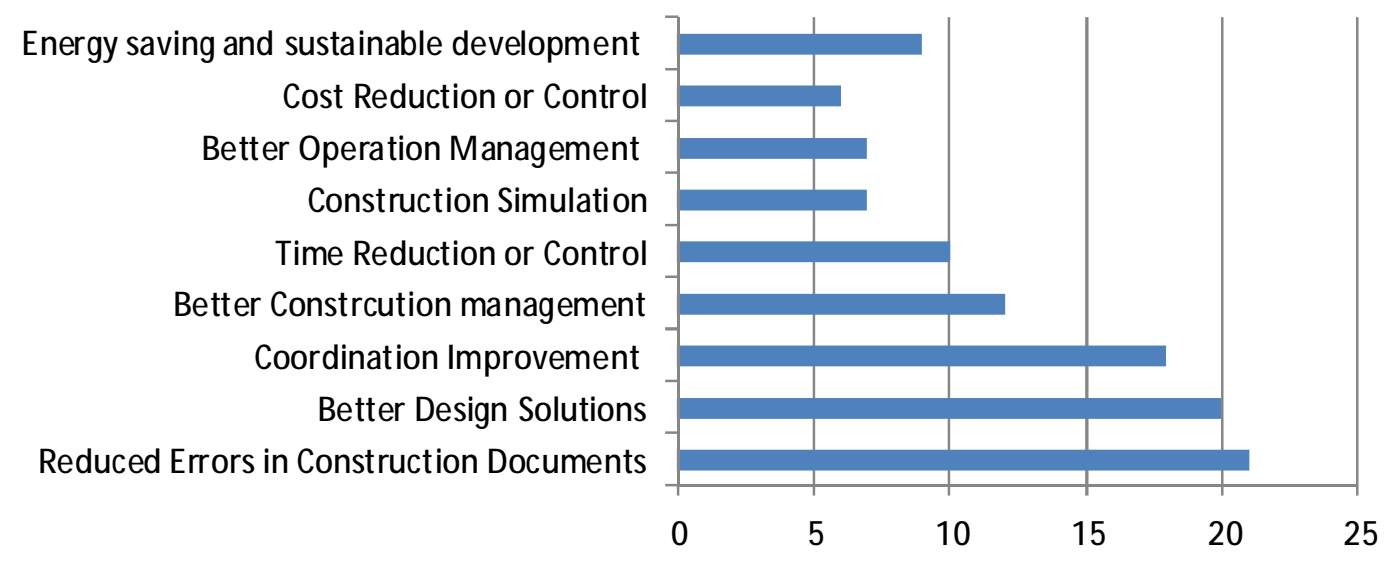

Fig.5 Benefits from BIM

\section{Analysis and Discussion}

BIM Strategy and Policy: Although there was not a real clear BIM strategy document released by the government or official organization in China, the government issued a series of policies to promote BIM development which can been regarded as strategy to some extent. The policies did lead a vigorous mass campaign on BIM in construction industry in China. However most of policies are lack of details or left the details to some standards which were mostly not published yet. Vague details make the practitioners of BIM feel disoriented. For example, according to the document of Guide to Promote Implementation of BIM in Construction Industry by MOHURD which is expected to be released recently, the government-invested public building projects which have total area of more than $20,000 \mathrm{~m}^{2}$ and the green building projects submitted to provinces for certification should adopted the BIM technology by 2016. However there is no a clear definition about what level can meet the demand of 'adopted the BIM technology' in the document, as we all know the BIM have different levels.

The most important policy support needed by BIM practitioners is to change the supervision procedure of construction projects to meet the demand of BIM implementation. The current policy demands that the design documents must be delivered to the contractors with 2D pattern in China. So even though the 3D model was building during design stage, it must be turn into $2 \mathrm{D}$ drawing before delivering that depress the enthusiasm of the designers to utilize BIM. Moreover, property and accountability of building information model is ambiguous. As a result, it is inconvenient for benefit distribution and responsibility division.

BIM Standards: The speed of developing standards should be accelerated. What the practitioners of BIM in construction urgently need is the BIM application standards to guide ways of using BIM tools. And the BIM tools developers are keen the foundation standards to unify the means of information exchanging format. Also the BIM standards developers need strategy standards to develop all the BIM standards to be an organized and coordinated standard system. However only one of the BIM standards was released already, others of the BIM standards were not finished yet in China.

There are three factors that affected the BIM standards developing. Firstly, to develop the standards needs developers who have rich BIM utilization or BIM tools developing experience, but there are not adequate talented professionals like that. Secondly, BIM standards get multiple industries involved, however it is difficult to get an efficient communication and coordination among construction industry, electronic industry, computer industry, internet industry and relative industries in standards. The interior coordination of BIM standards system is a key barrier for the standards developers. Thirdly, BIM standards developing of China are in an embarrass situation for the lagging of the Chinese native BIM tools (mainly software). On the one side, the application standards have a closed relation to BIM software. However the cases research in this paper shows native software only take a small proportion of the BIM software market in china. If the BIM application standards are developed based on the 
foreign software, it will depress the native BIM software vendors and influence the native software economic. Also there is a problem of national information security since the building information model involve various key information of building that should be controlled by own counties' company. On the other side, although the BIM market is keen for the national foundation standards to be released as soon as possible, it will have a limited impact on the BIM implementation after its releasing because the similar international standards have been developed. Rather than construction industry, the software industry is easier to break through the boundaries of countries and competed in an international level. Consequently, most of the software venders prefer to pay more attention to the relative international foundation standards rather than the national foundation standards. It is apparent from the example that the only one released BIM foundation standards, Industry Foundation Classes Platform GB25507-2010, didn't draw a significant attention in BIM market as expected in China.

BIM Technology: There are two sides of BIM technology: one is BIM tools developing technology and the other is the BIM tools utilization technology. We will discuss the former in this part and will consider the latter in the next part of 'BIM Application'.

As what the cases research shows, most of the software used in the Chinese BIM projects are developed by foreign company. Although there is first-mover advantage of the foreign software in China, it can't fit perfectly with the special management procedure system of Chinese construction industry. As a result, most of the foreign software limited in design stage or early stage of construction. So there leave some developing space for native software vendors to explore in construction stage or operating stage of building because they are more familiar with the Chinese construction management system. At the same time, the native software developers must improve the accuracy, efficiency and elaboration of the BIM software.

BIM Application: In china, BIM application mostly limited to large enterprises and mega-scale projects. As we all know, BIM skill learning and training, BIM team building, and BIM project awarding are efficient ways to prompt BIM application to spread BIM to middle or small scale enterprises and projects. In addition, there are several factors that should be valued in BIM application:

First of all, BIM have visible advantages on energy saving and sustainable development in construction industry in the light of cases research part, which can be an inducing factor of BIM implementation. Secondly, Industrialization of construction industry is a fundamental driver for deep BIM, and vice versa. According to the projects we collected, most of the familiarity can't be used repeatedly and that increases the workload and decrease the efficiency of BIM. Industrialization of construction industry, such as off-site production technologies, standardized products, elements, and module, will allow the decreasing of BIM cost and prompt its utilization. In turn, BIM also reduce cost and improve efficiency of industrialized projects; thirdly, the significant worth of BIM lies in the coordination of technology and management in construction industry. The management means of construction industry can't match to the BIM technology, especially fragmentation management. EPC (Engineering, Procurement, and Construction) mode of construction management is a talented one to be propitious to BIM because EPC bring a management centrality of BIM that allow the better coordination than decentralized BIM.

BIM Commercial Model: One of the most significant problems for BIM developing is lack of commercial model which heavily hindered the developing of BIM. The cases research shows benefiting from 'cost reduction and control' only accounts for a small rate of total ones. We all know that where BIM would bring benefit most is in the latter of construction and the operating stage, but BIM must be invested from the beginning of the projects. How to redistribute the benefit from BIM among all the participants during the life-circle of the project is the key to create a new active commercial model.

A valuable exploration of BIM commercial model is Shanghai Standard for Depth and Fee Scale of Building Constructions Design Information Model, in which the BIM design fee will be charged based on the depth of the modeling instead of being charged currently without regularity. It did have more great attraction for the BIM market than the government compulsory policy.

The current urgent need is sounder BIM tools developed to save cost or create benefit for the participants during the life-circle, especially for the early participants. But the BIM software 
developers lack of sufficient financial support to continue deeply the research of BIM software. Some capital-raising approaches, such as fund raising plan based on the BIM alliances, crowdfunded projects pattern or BIM incubation garden, can be considered to stimulate the capital injection to BIM industry.

\section{Conclusion and Recommendations}

Even though BIM has been embraced internationally, China has different approaches to prompt the implementation of BIM based on the special management system in AEC industry in China. This research concludes that BIM standards system, relative policy, BIM commercial model play crucial role in the BIM developing and implementation, especially consistency and coordination among them does more. Moreover, sustainable development, energy saving, industrialization, EPC management, sophisticated capital-raising approach have the potential to advance the development and implementation of BIM. What's most important of all, shifting of construction and supervision management pattern to adapt to BIM technology in AEC industry should be taken as soon as possible if China wants to keep pace with the countries leading the BIM field and be one of leaders in international BIM market.

\section{References}

[1]MOHURD, Annals of Construction Industry, China Architecture \& Building Press,2010

[2]LiJuan Chen, Hanbin Luo, A BIM-based construction quality management model and its applications, Automation in Construction, Automation in Construction 46 (2014) 64-73

[3]The British Standards Institution, Specification for information management for the capital/delivery phase of construction projects using building information modelling, BSI Standards Limited, 2013

[4]David Bryde, Martí Broquetas, Jürgen Marc Volm, The project benefits of Building Information Modelling (BIM), International Journal of Project Management 31 (2013) 971-980

[5]ZhengGuoqin, QiuKuining, Survey On BIM Domestic and Abroad Standard, Journal of Information Technology in Civil Engineering and Architecture, Vol.4 No.1 Mar.2012

[6] Harvey M. Bernstein,etc., The Business of BIM in China, Dodge Data \& Analytics,USA,2015

[7]Facility Information Council, National BIM Standard-United States National Institute of Building Sciences, the building SMART alliance

[8]CABR, Industry Foundation Classes Platform, Standards Press of China ,2010

[9]International Organization for Standardization, Industry Foundation Classes, International Organization for Standardization (ISO), 2005/2013 